Vol. IX - REVISTA DE HISTÓRIA - Ano V

\title{
CONFERENCIA
}

\section{COMO FOI BATIZADA A EUROPA? (1).} Colegas.

Já devo muito à Faculdade de Filosofia de São Paulo; mas, além disso, devo-lhe ainda alguma coisa esta noite: ela me recorda, o que é ao mesmo tempo agradável e melancólico, ela quer peremptòriamente recordar-me os meus primeiros amores, que foram pela geografia, em tempos mui longínquos, em que eu não era ridículo, pretendendo ter amores... Num momento de minha juventude, namorei, pois, de muito perto, a geografia; agradeço-vos o lembrardes isso, e vou tentar recordar-me de que, nesse tempo, fui ao menos meio geógrafo, para falar-vos dum problema de geografia, e eu o ventilarei sòmente como sei fazê-lo, simples e modestamente, isto é, como historiador que não é geógrafo, e procurarei, mostrarvos, que, do mesmo modo, pelos métodos da história e, enunciando problemas que a princípio parecem puramente históricos, pode-se chegar a tirar, tanto no conhecimento da geografia, quanto na sua prática, certo número de conclusões úteis.

Dei a esta conferência o título de "Como foi batizada a Europa?" e eis; com efeito, o que desejara dizer-vos a respeito: eis a questão que vos quisera apresentar:

Quais são as partes do mundo? - Logo que temos 7 ou 8 anos, fazem-nos esta pergunta e respondemos imperturbàvelmente: “A Europa, a Ásia, a África, a América e a Oceania". E isto se diz, precisamente em tôdas as partes do mundo.

Quais são, acrescentam, os limites da Europa? - Depois que temos 7 ou 8 anos, nos ensinam, dizem-nos: o Mediterrâneo ao Sul, o Oceano Atlântico ao Oeste, o Oceano Glacial ao Norte; mas, que nos dizem quanto ao Leste? Aí, hesita-se; enfim, geralmente, aca'ba-se por' indicar os Montes Urais. . . e partimos dessa bela' asserção. Dizem-nos isso, porque temos 7 ou 8 anos e somos crianças * (1). - Conferência pronunciada na Faculdade de Filosofia, Ciências e Letras da Unifrancês, traduzido por Hilda Penteado: de Barros. 
sem defesa contra êsses grandes diabos de homens e professôres que lá estão para nos martirizarem e nos imporem suas opiniōes...

Não perguntamos porque; e, durante anos, durante tôda a nossa vida, a noção da Europa, assim definida, já não suscitará problema para nós; ela fará parte do que chamo nossos "bens de família", ou seja, essa dotação em noções carcomidas, na verdadeira acepção da palavra, isto é, corroídas pelo tempo como as velhas moedas, cuja efígie já não se vê, e de que, desde o nascimento, o "homo-europeus" se favorece, o que significa haver necessidade de ser singularmente elucidada essa noção que faz parte dêsses velhos bens de família que aceitamos tais quais... Pois nada há mais obscuro, mais misterioso que essa noção sôbre a qual julgamos não haver necessidade de explicações; todos sabem isso.

A Europa, que é, pois? Limito-me a êsse nome de continente. A Europa, é uma noção de experiência? E' a comprovação efetuada por homens em momento aprazado, que, com efeito, existia realmente um conjunto de países, por um lado tão semelhantes uns aos outros, tão aparentados entre si e, por outro lado, tão diversos globalmente de todos os outros países, que os rodeavam, que um abismo os separava e um batismo se lhes impunha; a imposição dum nome sôbre êsses países tão semelhantes entre si apresentava-se, pois, muito a tempo, como uma necessidade; donde, uma palavra, cujo sentido seria preciso saber, uma palavra que é a Europa?

Para que os gregos tenham assim adquirido, por experiência direta, pessoal, a noção de algum modo necessária, a noção de evidência duma Europa, teriam sido necessárias duas condições realizadas:

Primeiro: que existisse realmente no globo um conjunto de países como acabo de definir, isto é, indiscutivelmente aparentados, cujo parentesco saltasse aos olhos, tão perfeitamente ligados uns aos outros e por tantos laços visíveis, que, à primeira vista, desse ao observador a impressão duma semelhança incontestável.

Outra condição: que um número assaz considerável de indivíduos tivessem sido postos em estado de verificar, por observação direta e pessoal, essa homogeneidade dum vasto território, essa similitude, e o contraste mui vivo que êle deveria oferecer com os outros países, com os territórios vizinhos. Digamos, teria sido preciso que homens tenham explorado os países em áprêço, não por acaso, mas regularmente, metòdicamente, normalmente.

Quanto ao que se refere à Europa, foi assim? Não, e pela meIhor das razões; primeiro - sabem-no e não vou divertir-me em arrombar portas abertas - não há Europa dada pela natureza. E' um fato e que diz tudo. Por tôda a parte os limites da Europa, ao menos o que pretendemos que sejam os limites da Europa, por tôda a parte passamos, não bruscamente, brutalmente, mas por uma 
série de transições insensíveis, da Europa à Ásia ou da Europa à África.

Averiguai o caráter africano muito claro de certos aspectos da Espanha Meridional, o caráter claramente asiático de certas paisagens da Rússia — na velha acepção da palavra Rússia Européia - da Rússia Oriental ou Meridional; verificar isso é uma futilidade sôbre a qual é inútil insistir; mas, por outro lado, comprovai as profundas diferenças que separam a Noroega da Itália, a Irlanda da Sicília, a Dinamarca da Grécia, Praga de Lisboa, Estocolmo de Nápoles; é trabalho supérfluo, sem dúvida.

Representemo-nos, no tempo longínquo em que o helenismo toma forma, os homens, ou movidos por insaciáveis curiosidades, ou por cuidados mui realistas de troca de mercadorias; representemonos, se bem o quiserdes, algum heróico pesquisador do âmbar, que se ia procurar muito longe, às margens do Mar Báltico; tornemos a ler Heródoto, no livro 4, capítulo 33: conta-nos uma história inteiramente assombrosa; fala-nos duma cadeia ininterrupta de povos iniciados que se estendiam desde o país dos Hiperbóreos - eram os ribeirinhos do Mar Báltico até Delos, na Grécia, o umbigo do mundo, e que transmitiam de mão em mão misteriosos objetos sagrados, envoltos em palha de trigo (particularidade curiosa que tem interessante valor folclórico), isso por um sistema de relações estabelecido desde o Báltico até a Cítia, da Cítia ao Adriático, do Adriático a Dodona, depois na Eubéia, depois em Teno e, finalmente, em Delfos - não sendo isso, absolutamente, imaginação de Heródoto; estando confirmada essa referência, ainda que fôsse sòmente por uma série de depósitos de barras de cobre que encontramos e assinalam, com efeito, aquêle caminho.

Que é que podia impressionar êsses ousados, êsses intrépidos aventureiros, no curso de sua marcha perigosa? Não se pode pensar que eram semelhanças e um ar de parentesco entre todos êsses países que se éstendiam desde o Báltico à Rússia Oriental e, de outro lado, até o próprio coração do mar Egeu; havia lá um ar de parentesco entre todos os países, os povos que nosso teórico viajante teria encontrado em sua viagem, desde a Grécia ao Danúbio, do Danúbio às florestas da Germânia, depois às margens do Báltico?

Não, mas o que teria impressionado seriam as diferenças profundas, contrastes extremamente pronunciados nesta Europa onde ainda hoje, apesar de séculos e séculos, milênios de trabalho persistente, - trabalho executado pelo homem que tende sempre para certa uniformidade - subsistem ainda diferenças enormes; existem ainda agriculturas sedentárias e pastores nômades, com economias transformadas em economias capitalistas mais ou menos adiantadas. 
Se nosso amigo possuisse um canhenho de viagem; se soubesse fazê-lo, ai teria inscrito menções, tôdas comparáveis às que, por exemplo, Stanley, quando jornadeava da África Oriental até o Congo, anotava cuidadosamente cada noite; ora era bem acolhido: por tribos pacíficas, que the traziam presentes, frangos; ora era muito mal recebido, a flechadas, por povos bárbaros. Para nosso. amigo isso teria sido a mesma coisa, por razões imprevisiveis: por que bom acolhimento lá e mau aqui? Nunca o sabemos; seriam. tantos problemas de psicologia difíceis de resolver.

Então vêdes: aqui, montanhas geladas; lá planícies baixas ecarregadas de sol; aqui, florestas e lá, ao contrário, pastagens verdes. Quando êsses homens voltavam, julgais, que iam dizer: "acabo de fazer uma bela viagem; acabo de percorrer a Europa?" Não. Muitos séculos mais tarde, quando Marco Polo fêz sua grande viagem, julgais que, triunfante, teria dito ao voltar: "Acabo de percorrer a Ásia?" - Absolutamente não. - Compôs simplesmente um livro que intitulou: "O livro do discernimento das diversidades". E' o título que temos em todos os velhos textos manuscritos de Marco Polo: "O discernimento das diversidades". Das diversidades, e não das similitudes. Vêdes, é um escriba que, mais tarde, um século após, introduziu com sua mão a palavra Ásia, traçando no cabeçalho do livro êste título resumido: "Abaixo começa o livro de Marco Polo e das Maravilhas da Ásia, a Grande, e da Índia, a. Maior e a Menor..."; é um belo título... Mas, que é a Grande Ásia? Mesmo ao escriba essa denominação não basta para abranger tudo de nossa Ásia. Êle diz com precisão: "A Ásia, a Grande, e a' India, a Maior e a Menor", que extrai do complexo asiático.

Quanto à exploração metódica e seg̉uida, na verdade, podemos perfeitamente considerar os gregos como notáveis exploradores - abstenho-me expressamente de dizer "como os primeiros exploradores"; pois temos de mais a mais, tôdas as razões para crer que a exploração do mundo se fêz muito antes dos gregos, por um povo completamente diferente, e como trabalhos recentes parecem bem permitir que o pensemos - teve por centro, não o Mediterrâneo, mas o Oceano Índico. Para lá convergem ao mesmo tempo - Extremo Oriente chinês, a Índia, o grande vale da Assíria, Babilônia, o Irão e, enfim, o Egito. Obcecados em nossa concepção mediterrânea do mundo, afigura-se-nos que o Egito é território do. Mediterrâneo; mas não, o Egito é tributário do Oceano Índico, pelo Mar Vermelho, sendo, não obstante, também um país mediterrâneo.

Eis, portanto, o Oceano Indico, para o qual convergem tôdas as mais velhas civilizações do homem, e estamos dispostos a descobrir provas, não escritas, mas deixadas por tôdas as espécies de instrumentos e objetos, que circulavam e foram utilizados em comum por todos êsses povos ribeirinhos do Oceano Indico; estamos dis- 
postos a chegar a esta noção de que é o mundo indiano que foi conhecido, que explorou e viu o comêço do que é a arte da navegação, a arte de fabricar navios e de servir-se dêles, lançando-se ao mar.

Portanto - digo a exploração metódica e seguida - podemos considerar os gregos, não como os primeiros, mas como notáveis exploradores; é exatamente a seu próprio esfôrço que se devem - nascimento e os progressos duma geografia viva; êsses curiosos. impávidos, que eram os gregos, fizeram recuar muito, fizeram fugir ante sua curiosidade, sempre penetrante, lúcida e crítica, os mundos fabulosos das velhas tradições, que perpetuavam e produziam o terror entre os homens; conseguiram bem repelí-los para além do Helesponto e do estreito que guardavam Caribde e Cila, e além das colunas de Hércules...

Semearam sôbre todo o circuito do Mediterrâneo, um rosário de cidades novas, filhas de suas principais cidades maritimas. Mas. antes que, partindo dêsses pontos privilegiados, tivessem conseguido alçar o vôo para se apoderarem das profundezas das terras, para subirem de novo os rios, foi preciso tempo, muito tempo...

Lembremo-nos de que Heródoto, êsse espírito tão crítico e inteligente, à procura duma testemunha autêntica que pudesse "jurar-lhe sob sua honra" - como diriamos hoje - que, com seus olhos, vira o mar cingir ao norte terras da Europa, declarou finalmente que a procurara durante tôda a vida e não encontrara uma. só vez.

Assim, os gregos não podiam inferir, duma observação direta e duma experiência pessoal, a noção duma Europa. Ao longo dum corte, praticado da Grécia para o Norte, a soma das diferenças se sobressai, e muito, no total, das semelhanças possíveis; ainda não haviam chegado os tempos duma tomada de posse científica da Europa pelos ribeirinhos engenhosos do Mar Luminoso. Então? Então, como acontece tantas vêzes, quando se quer remontar à crigem duma dessas noções correntes sôbre as quais adormece tranqüilamente a humanidade, despenseira de seus trabalhos, então nasceu a noção da Europa, primeiramente dum raciocínio abstrato; nasceu, se o quisermos, não duma observação concreta e positiva, mas de considerações, tôdas teóricas, que nada tinham que ver com a experiência.

Mais uma vez, vamos comprovar a derrota; vamos tocar o. hallali dessa concepção dum mister que determina as ações dos homens, os seus pensamentos, do mister que submete o homem a suas necessidades; não, não é a privações que o homem replica, direta e imediatamente, por mais urgentes que sejam essas privações.

Entre a necessidade e a ação há sempre alguma coisa que se interpõe, é a idéia, mesmo no domínio em que se deveria encontrar: 
a emprêsa mais imperiosa e mais absoluta da necessidade, o domínio do alimento; lembremo-nos do mesmo modo de certo número de fatos, ao menos curiosos, fatos de ordem histórica; citar-vos-ei um, é a conquista da Gália por Júlio César. O exército gaulês, sob o comando do chefe que elegera, Vercingetorix, encontra-se bloqueado, rodeado, de todos os lados, pelo exército romano, no alto do Monte Auxois, na região de Dijon; êle é cercado por Júlio César, que fêz em todos os lados do Monte Auxois uma linha de trincheiras, maravilhosamente construídas com estacas ponteagudas, estrepes, etc. com tudo o que é preciso para que pudesse conservar esta frente enorme com diminutas tropas. Encontramos, por escavações executadas no Segundo Império, e ainda aí se encontram, em tốdas. ruínas, os vestígios das trincheiras de Júlio César; elas existem, eu as vi, eu mesmo, e não são invencionices.

No entanto, êsses gauleses estavam lá; esperavam que grandes exércitos de socôrro gauleses viessem levantar o bloqueio; mas, passou-se um dia, passaram-se dòis, e surgiu a fome; êles haviam comido o que tinham, já não podiam receber o que quer que fôsse, o exército romano os rodeava: renderam-se, então. Não tiveram um instante a idéia de sacrificar, para se alimentarem, para prolongarem sua manutenção, sua resistência, para permitir a reunião das tropas de socôrro que operavam no centro do país, a idéia de sacrificar o que quer que fôsse dessa imensa cavalaria que lá estava à sua disposição... Porque, entre a carência, a necessidade de comer e o ato de matar cavalos para comer, que havia? Uma idéia, uma idéia religiosa, o velho tabu do cavalo, que ainda brinca no íntimo de nosso inconsciente, pois há muitos homens em França aqui, não sei se existe isso - mas ainda há em França muitos homens que têm uma espécie de recuo, de repugnância, quando se lhes propõe comer um bife de cavalo: é um tabu que se introduziu entre nós.

Quereis outro exemplo? Dei-o jár há muito tempo, em meu livro "A Terra e a Evolução Humana". Encontrei-o confirmado por um texto mui curioso sôbre os declives das grandes montanhas da Índia. Em todos êsses países de declives da Ásia e no mundo africano, essas tribos campestres, que impulsionam rebanhos diante de si e que, devido à sêca, morrem algumas vêzes de fome, em certos momentos de suas peregrinações, continuam a tanger diante de si pobres animais, que caem, êles também, mortos de fome, uns após outros; mas, jamais têm a idéia de sacrificar alguns dêles, o que quer que seja do rebanho; êle é intangivel, por que? Porque, ainda aí, entra a necessidade - nunca êsses homens sacrificam alguma coisa dêsses rebanhos, porque se interpõe a idéia de que é um capital, e aí não se deve tocar; provàvelmente também idéias. místicas que nos escapam. 
Com maior razão, e se é assim no domínio da alimentação, é assim desde que se trata de conceitos, de idéias, de vistas gerais sôbre o mundo. Esse problema está muito longe de ser elucidado, e quando, outro dia, eu dizia que precisamos de tantos livros e de tantos trabalhos sôbre coisas absolutamente essenciais, eis justamente uma delas que é essencial: a roda, que foi tão grande instrumento de progresso para as civilizações que a adotaram.

Há os realistas, os espíritos fortes, os malignos, que nos dizem: que mistério vêdes na roda? $\mathrm{E}^{\prime}$ um tronco de árvore que se retalhou em rodelas. Concordo; mas não é tão natural quanto isso. Primeiramente, retalhar troncos de árvore em rodelas, não é tão fácil; depois, quando temos a rodela, não temos a roda... Reuni, por uma peça de madeira ou do que quiserdes, duas dessas rodelas; não creio que isso rolará; isso talvez se arrastará; isso fará sulcos no solo; não é a noção essencial da roda... Mas, em presença dessa tese, que é a da necessidade, há uma outra, a tese dos folcloristas, que se apoia em documentos incontestáveis: a roda absolutamente não é uma invenção feita pelos homens, sob o império da necessidade; é a representação do sol, e houve, em inúmeras sociedades, rodas mágicas; rodas sagradas, antes que houvesse rodas motrizes; houve rodas que para nada serviam - para empregar a linguagem dos realistas - e muito antes que houvesse rodas que servissem para qualquer coisa.

As primeiras rodas, cuja representação temos em nossa civilização, são as rodas dêsses admiráveis carros solares, que foram encontrados na Alsácia, de maneira bastante curiosa, durante a guerra de 1914-1918; houve duas ou três descobertas assombrosas de carros sagrados com quatro rodas e sôbre a plataforma uma representação do disco solar, e desde êsse tempo, encontramos imagens análogas por todo o mundo. A imagem da roda inspira-se no sol e destina-se a figurar nas grandes cerimônias solares.

Aliás, a roda de oração existe por tôda a parte; por exemplo, entre nós, na Bretanha, quantas igrejas bretãs as conservam, as quais se assemelham a rodas de tornos de fiar, com travessinhas onde se ligam campainhas, e que tocam cada vez que se diz a oração; eu mesmo as vi na Bretanha, há uma dezena de anos; isso, portanto, não desapareceu, e isso funciona também no Tibete, do mesmo modo.

Quisera muito que um dia haja, enfim, alguém competente, que consagre os 10 ou 15 anos necessários à grande pesquisa sôbre a roda; que nos dotasse com um livro que nos falta e é essencial ao nosso conhecimento dos progressos da humanidade. Êle não seria utilitário; não colocaria a necessidade acima de tudo; colocaria a idéia entre a necessidade e a realização, a idéia, que sempre se encontra de novo na coisa humana; pois eu me embaraço em fazer 
essa descoberta, e experimentei tirar-lhes conclusões: o homem é essencialmente um ser que pensa...

Do mesmo modo, houve uma Europa teórica antes de ser uma: Europa geográfica; para satisfazer a que foi ela feita? A uma necessidade do espírito - antes que os homens se interessem em dar. a essa palavra uma acepção real, material, territorial, geográfica; que necessidade do espírito? A de analisar, de dividir e de recompor lògicamente o real; uma necessidade do espírito, o espírito grego, especìficamente grego; para os antigos helenos, que raciocinaram cêdo sôbre o mundo, êle tinha a figura duma esfera; se fôsse. uma esfera, como conceber, de maneira ideal, de algum modo, a distribuição das terras na superfície dessa esfera? Necessàriamente, do modo simétrico: isso era exigido pela lógica do espírito grego.

Tracemos um grande diâmetro num círculo, dum e outro lado; já não teremos de imaginar senão duas massas terrestres, eqüivalentes, tão compridas quanto largas, uma e outra, porque são essas. representações de comprimento e largura eqüivalentes que representaram no espírito dos homens, e que era uma espécie de necessidade lógica, de necessidade abstrata que se impunha a êsses geómetras natos, que eram os gregos; era preciso que assim fôsse para satisfazer à razão, e assim o foi, portanto, em teoria.

Mas o que existe só existe, na verdade, com a condição de ser nomeado, de receber um nome, o seu nome; com tôda a naturalidade, chamaram à ocidental, uma das duas massas, Europa; interpretai o que os fenícios chamavam Erebe, Oreb, rob, o Erebo dos gregos, o Gharb dos árabes; vêdes que o nome fêz fortuna duradoura: "O país do Poente, a região que vê a obscuridade cair sôbre si, quando o sol desce".

Do outro lado, a outra massa, que era necessàriamente, por suas necessidades de lógica e para que tudo fôsse satisfatório ao espírito dos gregos, a inscrição da terra nesse círculo que era o. mundo, em duas partes iguais, a outra massa foi a Ásia, Ásia, o país do Oriente, País do Sol Nascente.

Quando isso? Bastante tarde relativamente; pois o nome de Europa não se encontra uma única vez nos poemas homéricos, assim como o nome de Ásia. Encontrareis indicado, mas não é verdade, que se faz menção da Ásia no verso 461 do $2 .^{\circ}$ canto da Ilíada; mas não se trata da parte do mundo, e sòmente duma cidade de Asis ou Asos, na Lídia.

Nesse poema geográfico, que é a Odisséia, nenhuma idéia de continentes distintos. Essa idéia, è essa aparição da palavra "Europa", para exprimir um dêsses continentes distintos, só é expressa pela primeira vez mais ou menos no ano 520, antes de Jesús Cristo, por êsse grande Hecateu de Mileto, de quem Abel Rey, em seu belo livro sôbre a "Juventude da Ciência Grega", página 498, nos: 
fala com entusiasmo, como do homem que fundou a ciência histórica fora de tôda a inspiração mítića. Ora, em sua "Volta do Mundo" - assim traduzo o grego "Periddos Gês" - êle consagrava um livro à Europa, um livro à Ásia, um livro a uma terceira parte do mundo, cujo nome começava então a entrar em uso: a Líbia, isto é, a região donde vem o vento do Sudoeste, o vento Chuvoso; por que? Por que se descobriu a Líbia? Absolutamente não.

E' por que disseram, há a Europa, que vai, em baixo, do fundo do Mar Negro, onde os gregos foram muito cêdo, desde o fundo do Mar Negro, onde desemboca o Eufrates, que separava o continente, para ir às Colunas de Hércules, era preciso viajar; sabiam que era longe, muito longe; que eram necessários dias e dias de navegação, em todo o caso, até Caribde e Cila. E'm baixo, havia a Ásia, mas não podiam prolongá-la; estavam apenas no meio dessa massa do Norte, que era a massa da Europa; então, juntaram a essa Ásia as partes necessárias para que a Ásia e a Líbia reunidas fôssem mais ou menos o eqüivalente da totalidade da Europa.

Considerações do espírito, e destinadas, cêdo ou tarde, a ser desmentidas pelos fatos. O inteligente Heródoto, que nasceu pouco depois da morte de Hecateu, em 484, já tinha a exata intuição disso, e nos diz:

"Ignoro - vide livro 4, página 45 de suas Histórias, - em que se puderam apoiar, sendo a terra uma, para lhe impor três nomes: Europa, Ásia, Líbia; ignoro porque êsses nomes são nomes de mulher, e porque o Nilo do Egito, o Fasis da Cólquida, foram considerados como limties (ao Fasis de Alos, alguns substituem o Tánais, rio de Meótis, e o Estreito Cimério); não posso saber, conclui melancòlicamente o grande viajante, o nome dos que determinaram êsses limites, e onde colheram essas denominações... Aliás, ninguém se assegurou, de maneira precisa, positiva, se a Europa, no Levante, a Leste e ao Norte, é bem rodeada de água..."

E' sempre sua obsessão; não quer aceitar sem provas; livramo-nos disso, dizendo: "são as Fábulas de Heródoto"; não, é o. espírito mais crítico, mais inteligente que há no mundo; mas a necessidade the fêz formular questões que não podia resolver, nem. ninguém de seu tempo. Diz ainda: "Mas há um fato certo, a Europa, só ela, é mais considerável que os outros dois continentes reunidos; ela preenche o mesmo comprimento; mas sua largura é mais considerável que a largura da Ásia e da Líbia reunidas".

Vêdes, êles são informados do que, primeiramente, foi uma. condição puramente teórica, e depois a realidade, à proporção que a conhecem melhor, vem trazer-lhes numerosos desmentidos; lá estão êles entre a realidade, dum ládo, e a existência teórica, a noção teórica de continente, de outro. 
Aqui me detenho, não tendo por escopo descrever um capítulo de história da geografia, e seguir tôdas as vicissitudes da Europa. Meu intento é mostrar que é uma consideração teórica do espírito e de modo que, por uma necessidade abstrata, os gregos, havendo formado a noção de continente, deram a um dêles o nome de Europa; ao outro, o nome de Ásia; a um terceiro, o de Líbia, sem nenhuma comprovação geográfica real.

Feito isso, deixaram que seus sucessores, imbuídos da noção profundamente absurda e por conseguinte, tanto mais vivaz, de continente, a deslindassem - e quando um absurdo entrou nas escolas, sabemos todos que daí já não sai durante séculos e séculos...

Tendo sido adquirida essa noção de continente, era necessário tentar adaptar, de qualquer modo, as realidades geográficas, cada vez mais conhecidas; a noções que nada mais queriam dizer, geogràficamente falando...

Direis que são velhíssimas histórias: mas não, ainda no século XVIII qual era a obsessão, a grande obsessão dos espíritos aventureiros? Por que houve essas explorações maravilhosas dos inglêsses, dos franceses, através do Oceano Pacífico? Que é que impeliu êsses homens a fazer êsse trabalho? Uma necessidade, certamente não; não, não se pensava um instante na mística do continente, da massa continental requerida pelo equilíbrio e pela simetria; que era preciso descobrir? $O$ grande continente austral, do qual se dizia que o holandês Tasman fizera o périplo, e que formava uma formidável massa ao sul do Oceano Pacífico; era preciso descobrí-lo, e já se desenhava, com precisão, o mapa em 1744 (John Campbell, um inglês), um mapa tão conjectural quanto extraordinário, esperando-se que o nosso grande Buache, geógrafo de Napoleão I, o mostrasse, dez anos mais tarde, ligado à América do Sul pela Terra de Drake, e à África pela Terra da Circuncisão.

Era preciso descobrir o Continente Austral, que era necessàriamente lógico, pois, já que, nos mapas, se possuiam traçados de pequenas terras, poder-se-ia concluir disso que eram ilhas; mas não, era preciso reuní-las e delas fazer um continente que ninguém jamais vira... mas que era uma necessidade, porque era necessário um contrapeso à massa dos outros continentes do norte do Pacífico: êsse contrapeso, procuravam-no numa massa terrestre que se imaginava tão bem quanto possível.

Era o intento de Cook, quando partiu, em missão do rei da. Inglaterra, para descobrir o Continente Austral; franceses também partiram para isso.

Restabeleceram idéias: vêem-se realidades e revogam-se opiniões; é o grande alimento da humanidade no século XVIII; mas hoje, não é comovente, e um pouco humilhante para o espírito, ver os esforços desesperados que tentam nossos inventores de manuais, 
para adaptarem a nossos conhecimentos, assaz resumidos sôbre o mundo, noções antiqüiadas, desprovidas de todo o sentido?

Abri alguns dêsses manuais, antes de vir a êste país, e dêles vos apresento uma citação:

"As terras emersas dividem-se em três continentes: o Antigo, - Novo e o Continente Austral; julga-se que existe, nas regiões antárticas, um $4 .^{\circ}$ continente; êsses continentes são de extensão mui variáveis; o maior é o Antigo, que abrange, êle só, 80 milhões de quilômetros (admirai a precisão dêsses número - quanto abrange essa realidade, cujos limites não conhecemos...). Cada um dêsses continentes se compóe duma ou várias partes do mundo. No Antigo, distinguem-se a Ásia, a Europa, que não é senão a mais extensa das penínsulas asiáticas e a África, ligada à Ásia por um istmo muito estreito, hoje cortado pelo Canal de Suez...".

Felizmente, os autores têm, acêrca disso, um arrependimento crítico:

"Essa divisão é artificial por diversos motivos" - dizem êles - notai, incidentemente, que êles não aplicam êsse epíteto de artificial à noção de continente; aplicam-no às partes do mundo. "Elas são artificiais, e seus limites variaram no século XVII; por exemplo, era o Don o limite oriental da Europa; hoje, dizemos o Ural. E a Insulíndia, à mercê das convenções, ora se inscreve na Ásia, ora na Oceania".

Podem-se Alivertir os pobres rapażes, as pobres moças que lêem isso? Isso, aliás, não os distrai absolutamente; podemos divertir-nos em escrever isso? Vêdes, quando uma tolice foi proferida, não a eliminamos; tendemos a justificá-la razoàvelmente confiamos a textos a noção irreal e absurda de continente; Hecateu de Mileto diz lògicamente, mas êle nada sabe: "deve haver tanta terra em cima, quanto em baixo", mas, já não o admito entre nossos compatriotas.

Transportemo-nos um momento a outro mundo, outra esfera, fora da Europa: Europa, Ásia, África, concepções de ocidentais, concepções dos gregos e dos romanos, satisfazendo-se-lhes a necessidade de generalizar, de substituir o real pela lógica. Ao contrário, vêde os chineses, tais quais Granet nô-los fêz conhecer, em dois livros clássicos admiráveis, não sòmente para conhecer os chineses, mas para nos conhecermos em comparação do que êle nos diz dos chineses, de nossas idéias, de nossos sentimentos, de nossas maneira de proceder, em relação à sua civilização.

Para êles, não se trata duma terra esférica, com a circunferência ocupada por um rio contínuo, e que admite necessàriamente, para a ordem, para a simetria, para o repouso do espírito satisfeito, massas continentais em perfeito equilibrio. 
Não, para os chineses, é o Tempo que, por ser cíclico, evoca e conserva a idéia de círculo. O espaço é concebido por êles como um quadrado, e a terra, que é espacial, é, portanto, igualmente quadrada; vós todos tendes visto, nessas velhas plantas de cidades chinesas, que o muro exterior que engloba o principado é quadrado, assim como o muro do recinto da cidade, e quando os chineses vão para a guerra, o contôrno de seus acampamentos é quadrado.

Além dos quatro lados que assim emolduram a Terra dos Homens - isto é, a que pertence aos chineses - encontra-se uma como que franja de regiões vagas, que se chamam os quatro mares; nesses quatro mares habitam, respectivamente, quatro espécies de "bárbaros", que têm nomes muito complicados; suponho, neste momento que me torno chinês; os bárbaros, portanto, são os nãochineses (pois é um fato, verificado em tôda a parte, sob tôdas as latitudes e em tôdas as épocas históricas: nós somos os civilizados, e os outros são os bárbaros), aparentados com diversos animais, mui expressamente designados; os bárbaras dos chineses participam da natureza dos animais; e quando se reune o mundo inteiro, êle forma, fora do conjunto quadrado que os chineses guarnecem, um quadrado exterior, que engloba o quadrado fundamental dos chineses.

Não há espaço, nessa concepção, para alguma coisa que resulte dum fato de experiência, mas sòmente duma idéia preconcebida; não há lugar para uma divisão geográfica do mundo em continentes.

Isso quanto aos chineses; mas, quanto aos inđianos? Em sânscrito; como em árabe, a palavra que traduzimos por "continente" exprime a noção de ilha, e o mundo consiste em certo número deś'sas ilhas concêntricas, separadas por mares de leite, de mel, etc. A ilha central, rodeada por um mar salgado, tem no centro uma grande montanha, e a India está ao pé dessa montanha; o resto, realidades e imaginações, arranja-se, como se pode, segundo as épocas e os sistemas.

O espírito indiano não tem exigências geométricas como o espírito grego; êle deixou os povos, míticos ou reais, arranjar-se inteiramente ao redor, numa ordem qualquer.

Não parece que as experiências dos indianos os tenham, durante muito tempo, imbuído da noção de Europa; Açoca, um dos grandes sábios da India, enviou missionários budistas até às bordas do Mediterrâneo; mas não se sabe que se tenham preocupado com a questão, nem com a Europa, nem com a Ásia.

E quando chegaram à India invasores, os hunos, os turcos, os mongóis; ou quando se colonizou a Indochina, não resultou dêsses contactos nenhuma mudança na cosmografia tradicional dos indianos. 
E hoje? Sem dúvida, houve importações de idéias ocidentais; os diplomatas, os ministros, os intelectuais dêsse mundo indiano tomaram parte em reuniões internacionais, e viram, pelo menos, as pequenas etiquetas atrás das quais se classificam as nações; mas nunca etiquetas dos continentes... Eles se familiazaram com nossas concepções lentamente, difìcilmente.

Hoje, parece, há uma noção de Ásia, que tomou sentido reivindicativo bastante claro, em face da Europa e da América do Norte.

No Japão, principalmente, utilizou-se essa noção de Âsia na propaganda política; mas, dizia-me um dos grandes indianistas, Jules Bloch, quando eu o interrogava sôbre êsse assunto: "Há 30 anos, quando eu estava na India, custava-me muito fazer compreender, a meus interlocutores, que a França, que não era a Germânia, não era também uma província inglêsa, e continuo, aí de mim!, a receber ainda, de quando em quando em Paris — é um "aí de mim!" econômico, baixamente econômico - cartas que me chegam fielmente, porque não são suficientemente seladas, porque o carteiro vem reclamar o que lhes é devido... Elas são seladas como para a Inglaterra, mesmo por pessoas que sabem ler, que sabem escrever o inglês, e que têm diplomas de Universidades inglêsas".

Vêdes a admirável tenacidade da Humanidade; é o que eu queria demonstrar-vos esta noite, tomando essa noção de Europa, cuja origem não se procura bastante. Tenho bem vontade de acrescentar que é, do mesmo modo, curioso que essa noção de Europa, que ainda hoje procuramos, porque, enfim, fala-se muito da Europa em nossos jornais, nos congressos mundiais e às margens do Isle, em minha boa e velha cidade universitária de Estrasburgo, onde se realiza atualmente um dêsses congressos; é curioso que essa Europa, ninguém seja capaz de conferir-lhe uma definição inteligível, que signifique alguma coisa... Desde a origem, ela foi uma etiqueta que perpètuamente, através de tôda a História, procurou uma realidade sôbre a qual possa colar-se finalmente.

Esperemos que o Congresso de Estrasburgo e os congressistas fornecerão enfim, um substrato a essa noção, e que ela, afinal, poderá ser-lhe aplicada; formulo êsse voto de todo o coração, embora permaneça um pouco pessimista; mas a Humanidade se conserva aferrada a suas velhas idéias. A Humanidade morre, e depois renasce... Morre e se perpetua; é como a velha Guarda de Napoleão — a Humanidade morre... mas não se rende nunca...

LUCIEN FEBVRE

do Instituto de França. 